\title{
Information Technologies in Culture and Education: Image Processing Issues
}

\author{
Aleksey Iosifovich Vinokur ${ }^{1}$ \\ ${ }^{1}$ Doctor of Engineering, professor of Cybernetics and IT security Department of National Research Nuclear \\ University MEPhI (Moscow Engineering Physics Institute), Russia
}

Correspondence: Aleksey Iosifovich Vinokur, Doctor of Engineering, professor of Cybernetics and IT security Department of National Research Nuclear University MEPhI (Moscow Engineering Physics Institute), Russia. E-mail: Alex.Vinokour@gmail.com

Received: February 22, 2015

Accepted: March 15, 2015

Online Published: April 7, 2015

doi:10.5539/mas.v9n5p314

URL: http://dx.doi.org/10.5539/mas.v9n5p314

\begin{abstract}
One of the most important applications of information technologies in culture and education is content creation by digitizing objects of material culture (MCO). This content is named digital heritage. Rather large databases have been created. Digital heritage processing means for the purpose of culture and education are developed and are being developed. Works regarding digitization and development of software and information systems of digital heritage of various applications is carried out under government orders and at the initiative of noncommercial associations, private persons, and companies, and sure enough it will be in progress for many decades.

Creation and use of digital heritage is a vast area of human activity, which dramatically alters humanity mentality, culture, ways of education and so on. The activity has many aspects - political, legal, technical, scientific, economic and others, each of which is being actively developed. Therefore, any studies in this direction are relevant.

The majority of digitized MCO are kept and used in the form of digital images. When working with digital images two problems of copy quality evaluation arise: content transfer accuracy and form transfer accuracy. Nowadays there are no legal principles and approaches to rating these non-quantitative indicators. At the same time the issue is important and relevant since different standpoint regarding the notion of "quality" and different aims pursued by creators and distributors of the content as well as users' interests may lead to serious conflicts and become effective means in cyber wars.

The paper offers classification of correspondence of MCO original and its digital copy by content, and also considers some technical aspects of digitization technology and subsequent visualization of images that allow providing high technical quality of copies and avoiding repeated digitization in the future.
\end{abstract}

Keywords: digital heritage, digital copies, digital images

\section{Introduction}

Extensive use of information technologies is one of main and most important development trends of modern cultural and educational space. The intensive process of digital content creation by means of copying material culture objects (MCO) in the form of various media systems is in progress. This process has many aspects and affects almost each person as a producer and consumer on the information market especially in the area of culture and education. Process immensity and information impact on value system (MacDonald, 2006) suggest that digital media means will become determinant factors of the future destiny of humankind (Hauttekeete at al., 2011).

In the process of development new problems and tasks are exposed, many of them are related to image information as an important component of digital heritage. Moreover, the share of image information according to the specialists (Note, 2011) exceeds $90 \%$ of digital heritage content.

Analysis of the process of digitization, processing and demonstration of image information suggests that content presentation form, technical quality of digital copies, information medium of their presentation essentially influence perception of information and, consequently, is of the same importance as content (MacDonald, 2006). 
The paper deals with a number of technical aspects of this process relating to image information.

Image information takes in public life increasingly important part. Various systems of images search and demonstration become ever more widespread, particularly in respect to digital heritage and education. Different aspects of digitizing and distributing material culture objects are addressed in many studies. For today general approaches to generating information systems for libraries and archives are well developed. For example, (Kenney \& Rieger, 2000). Organizational issues of effective digitizing are developed (Lee, 2001). The matters of copyright when digitizing collections are addressed (Hughes, 2004). More general legal questions of ownership are also considered (Liu, 2001). Features of photograph collections digitalizing and working with are studied (Ritzenthaler \& Vogt-O'Connor, 2006). General complex approaches to audiovisual digital collection formation region-wide as exemplified by Flanders (Hauttekeete et al., 2011) and Italy (Caffo, 2014) are studied. The use of search systems and metadata of search means in education (Styliadis, 2009). The use and creation of multimedia documents in education and library information systems (Krstev \& Trtovac, 2014). Issues of digital heritage dissemination in the Internet are considered by the example of archeological data (Meyer et al., 2007). The use of various technologies for three-dimensional reconstruction of archeological and glass artifacts (Tsirliganis et al., 2004). Concepts of open data and systems, opportunities of free access in information economy (Simón et al., 2014) and studies in humanities (McLeod, 2014) are discussed. The issues of perceiving MCO copy by the user depending on search motivation (Skov \& Ingwersen, 2014). Practical recommendations and theoretical approaches to digital collection creation are thoroughly elaborated (Note, 2011). E-learning in Italy (Iannucci et al., 2011). Rather complicated search technologies based on cognitive approach are studied (Matusiak, 2006).

\section{Methods}

General trends are clearly traced in this diversity and it's possible to point out several key general problems, solution of which depends on the images quality and information systems operation in general assessed by the end consumer, that is of prime importance for cultural and educational space, which forms the world-view of current and future generations.

\subsection{Tendencies of Working with Image Content}

The first significant tendency is globalization of visual content. It's fair for all kinds of images and related information. Static and animated images; polygraphic copy prints, photographs, cinema and video; copies and originals, archived and modern ones. One of the most important indicators is quantity and diversity of the content. It should be noted that we discuss digital collections and therefore it's necessary to divide images into three groups. There are images already available in digital form, when working with them it's necessary to look after possibilities of their homogeneous presentation and reproduction (issues of formats keeping and "mountability" when visualizing); images represented in analogue media (cinema, photo, video, polygraphic, pictural and other images), initial problem in this case is digitization, i.e. digital registration of images. It is important to note all photographic and cinematic archives collected for more than 100 years subject to transfer into digital form. Information scope is large enough - more than century the world has toiled at their creation. Suffice to give an example of Russian National Film Foundation archive or French film archive in Bua D'orsi. Both archives contain about a million of 10 minutes video. That's why we shouldn't consider this issue a specific, short-time or casual one. The digitization of image archives is a complicated task not only technically but also conceptually. Finally, the third group consists of physical objects (pieces of pictorial art, sculptures, material culture objects, archive documents, etc.), images of which are not recorded neither in a digital not in an analogue way. The most important task is registration.

The second tendency is cross media of system and technology. The digital image stored in database is used for different visualization systems. Generally, technical characteristics of registration process do not conform to technical capabilities of demonstration process. The cause is possible lapse of decades between registration and demonstration. Moreover, we want to view the same image in small display of a mobile phone and in large screen for demonstration in a conference hall. The diversity of viewing devices and unknown in advance technical quality of registered digital images require individual approach to each chain: "original - registration processing - reproduction - image". At this point there are tasks relating to characteristics of visual perception and feasibility of artistic design in different image media.

The third tendency is fusion of image information heterogeneous by technical characteristics in the context of one edition (collection, film, literary work). It also can be unification in the framework of combined image. Differences of united images may be about resolution, dynamic range, color coverage, colour and light shooting conditions influencing observer's adaptation, frequency characteristics of registering camera, etc. There are problems concerning images "mountability". 


\subsection{Digital Copies Quality Problem}

Digital copies quality problem is also extremely important issue regarding digital content creation. The distinctive feature of the modern stage of digitization technology development is its availability and perceptible imperfection. The more available and cheaper technologies and equipment, the greater profit during mass large-scale digitization and the greater differences by all most important qualitative indicators.

Essential trouble is that expensive state-of-the art technologies in 20 years will not most likely meet our idea of copy's proper quality in comparison with visualizations systems and any other demonstration used by that time (Caffo, 2014). Nonconformity of digital copy's quality to original will unfailingly lead to the need of repeated digitization. The process of futile digitization will become cyclical unless we adhere to the need for special technical means use to provide dead storage of the digital copy, which in a sense faithfully copies its digital original.

\subsection{The Material Culture Object and Its Digital Copy Correspondence Problem}

MCO low-quality copies are a pressing problem. Users explain their existence with defective technologies of digitization or commercial aspect (the lower prices - the lower quality) (Skov \& Ingwersen, 2014). Meanwhile, their manufacturing and distribution cause damage to the national security of owner-state of copied MCO. It's one of common techniques of information war - creation of misapprehension of opponent's culture and mentality by means of distributing digital copies, which reflect the original essence fairly inaccurate (Cacciotti et al., 2015). Simplified detractive presentation of material culture objects creates wrong ideas of people and country. Conscious actions cause profanation and reduction of achievements. There are frequent attempts (sometimes successful) of historical event revision (Panarin, 2004). It's necessary to classify MCO digital images in order to create scientific approach to this problem examination.

\subsection{Images Technical Quality Indicators}

Following the prevailing tradition of the Nuberg-Artyushin school we distinguish three main aspects of image technical quality (Nuberg, 1948) and (Artyushin, 1970).

- frequency content (small detail and sharpness)

- tonal content (tone rendering and light-and-dark range)

- colour content (color rendering, color shade and satiation).

The indicators are given in order of importance for subjective estimation of image quality by the observer. All represented quality indicators can be quantitatively described and in such a way that we have range, for example, range of tones, range of chromacity, etc. for each image by each of indicators. The set of reached values ranges by all three indicators can be named reproduction coverage on the analogy of the notions of color coverage and dynamic range. It's of importance that image presentation in a digital form resulting from registration and image - result of visualization process - can also be described by ranges corresponding to each of quality indicators. In the first case one may consider original coverage - the material culture object, and in the second case - about image coverage. Reproduction coverage of registration process and reproduction coverage of visualization process are defined in a similar manner - as indicators ranges, which can be potentially registered by registration system and can be visualized by a given visualization system, correspondingly.

\subsection{Structure of Images Registration and Reproduction Systems}

The chain "original - registration (digital image) - visualization (demonstrated image)" is main object under consideration in the systems of image processing and reproduction. Any of classes of non-digitized images can be considered original: physical objects (shooting objects) or analogue images in various media. In both cases we'll examine them as registration objects.

Generally, the system of digital processing and imaging can be schematically represented in the form of linear sequence of the following units (Belousov, 2003), which is shown in Figure 1

- Unit containing registration objects of various class from various sources, each of them is characterized by reproduction coverage

- Registration unit, the working result of which is a digitized image characterized by registration coverage

- Processing unit, the working result of which is a digital image modified to common generic format, designed for archival storage, use to solve search problems of all kinds, for visualization and presentation. It's important in the course of processing not to reduce reproduction coverage of registered digital image as compared to registered image coverage. 
- Visualization unit, the working result of which is a master copy - digital file, reproduction coverage of which corresponds to reproduction coverage of selected reproduction system. There are a lot of possibilities including various printed forms (photographs, printing), electronic images on screens of monitors of different types, and various projection images. In a general way, this unit should be opened by the system with the advent of new technology and image depiction techniques the corresponding procedure of visualization will be soon implemented.

- $\quad$ Demonstration unit, the working result of which is an image (printed copy or optical or formed as a result of dynamic processes), which corresponds to digital file of visualization.

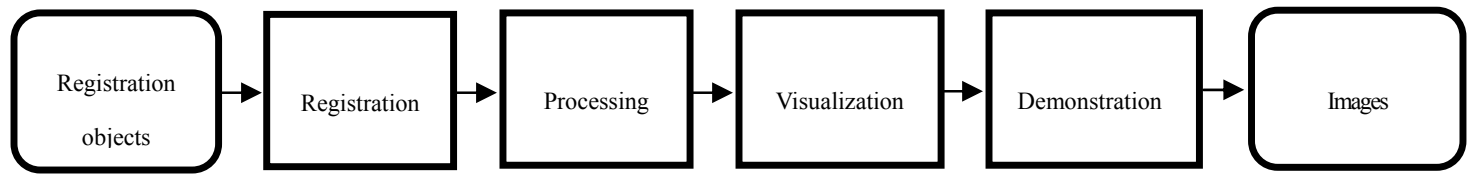

Figure 1. System of images digital processing and reproduction

\section{Results}

\subsection{Classification of Digital Copying Accuracy of Material Culture Objects}

We suggest the following classification of MCO reproduction accuracy by its digital copy.

Facsimile accuracy. It's a certain perfect characteristic which is presented in complete identity of digital copy and original in terms of undistinguishability when viewing and listening in any conditions of perception (any user's adaptation), in any perspective and scale. In real life differences are only detected by reproduction system (visualization or audio system), this property is fair for all reproduction systems. Within its limits facsimile accuracy should contain process determination for a material copy indistinguishable from its material culture object and implement this undistinguishability for each video and audio reproduction systems. Facsimile accuracy defined in such a way cannot be apparently achieved to the full extent. However, the notion itself is useful as it defines an ideal which we should follow when running actual technologic processes of digitization and visualization. For today maximum technically possible approach to facsimile accuracy is provided at the stage of digitization, and requirements for reproduction coverage are defined by sensor systems features and original - material culture object - itself. In other words, there are terminal parameters of registration system (digitization), exceeding them has no reason if we take the person as a consumer of digital copy.

Collection (artistic) accuracy. This kind of accuracy is for practical needs when determining digital copy suitability for distribution. Group of experts admits that given copy when using given reproduction system provides a correct impression of artistic merits of the object of material culture. Thus, each time a pair is examined- digital copy and system of its reproduction. Very good digital copy can be unacceptable in combination with reproduction system of low technical quality. And vice versa, the best reproduction system cannot "brisk" poor digital copy. It's necessary to carry out work for characterization of both through process and minimum requirements to collection digital copy and proper reproduction system in particular. Perhaps, it makes sense to introduce classes or categories.

Profanation. This kind of accuracy is for removing digital copies unfit for distribution. Group of experts admits that given copy when using any reproduction system provides warped conceptions of artistic merits of the object of material culture. As a result of its demonstration profanation - detraction and distortion of artistic content takes place, that eventually poses a hazard for national and world culture. It's necessary to formulate threshold technical requirements knowingly isolating some digital copies. However, one should keep in mind that final decision is made by a group of experts.

\subsection{Essential Problems of Images Registration and Reproduction}

\subsubsection{Matching Dynamic Ranges}

From the very beginning all reproduction systems were focused on providing proper reproduction, i.e. on assuring compliance of original (source image) reproduction coverage to its image - system work result. It was soon found that contrast (dynamic range) for the majority of originals exceeds reproduction system capabilities (Yashtold-Govorko, 1968), and in such a way "constant" problem was revealed - need for tonal transformation to reduce displayable tones interval. When solving this problem, reduction initial contrast to set value is limitation. Target function - creative task solution - is not formalized in majority of cases. Subsequently, there 
are a lot of works wherein there's optimal tonal conversion for one or another particular case (Nuberg, 1948), (Artyushin, 1970), (Hunt, 2004), (Fairchild, 2004).

\subsubsection{Matching Reproducible Colours Coverages}

Impossibility to reproduce some or other colours caused by synthesis method, synthesis paint (dye) properties or base emissions makes additional problems, which cannot be solved by tone conversions. In other words, the first problem is mismatch of original (source image) colour coverage and reproduction system capabilities (Note, 2011). Reproduction accuracy classification offered by Nuberg N.D. (Nuberg, 1948) became the scientific basis for solution of this task. To date this classification is much used in polygraphic industry and other reproduction systems, where it is conceivable that the original and its image are viewed under the same conditions, namely, with the same state of adaptation to viewing conditions. As it is known, our perception of visual stimuli depends not only on stimuli size but on vision system state, which is typically characterized by the level of adaptation (Aleksandrov, 1998). Hunt offered classification of reproduction accuracy with due regard to differences in the conditions of viewing original and image (Hunt, 2004). It is not universal one, but it reflects most common situations. Some its subsets are realized in colour management system when making ICC profiles for some special cases (Fraser, 2003). Further development of this trend was reflected in constructing perception model parametrically depending on viewing conditions (Fairchild, 2004). The model doesn't forecast all sight effects currently known from sensory physiology, but its application brings satisfactory results in many cases. There are other approaches to the problem of dynamic range reduction Barladyan, 2004), which also yield effective results for many images.

It should be noted that all colour management systems are based on reproduction processes modeling and subsequent experimental model setting to specific technology process. At this point there are various approaches, the choice depends on colour synthesis method and its features (Artyushina, 1989, 1996, 2005).

\subsubsection{Reproduction of Frequency Content}

It should be stated that all above-mentioned relates only to tone and colour aspects of image quality evaluation, i.e. to large details reproduction and leaves frequency content - reproduction of small details and contour information. Nonetheless, the aspect of frequency content is of paramount importance when evaluating image quality. As a rule, frequency filtering, which provides relative increase in small detail reproduction contrast, is used to improve small details reproduction and contour information visibility. Based on the Nuberg's duplicational theory we offer an approach that provides accurate reproduction of threshold difference of small details tones subject to original and image viewing conditions (Artyushina and Vinokur, 2005). This approach makes is possible to keep all contours of the original with relative sustention of their contrasts and eliminates the possibility of originating visually discernable new contours. The basis is division of the original into high-frequency and low-frequency images, and then division of high-frequency image into low-contrast and high-contrast components and their subsequent separate processing. It can be schematically represented by the chain of transformations shown in Figure 2. 


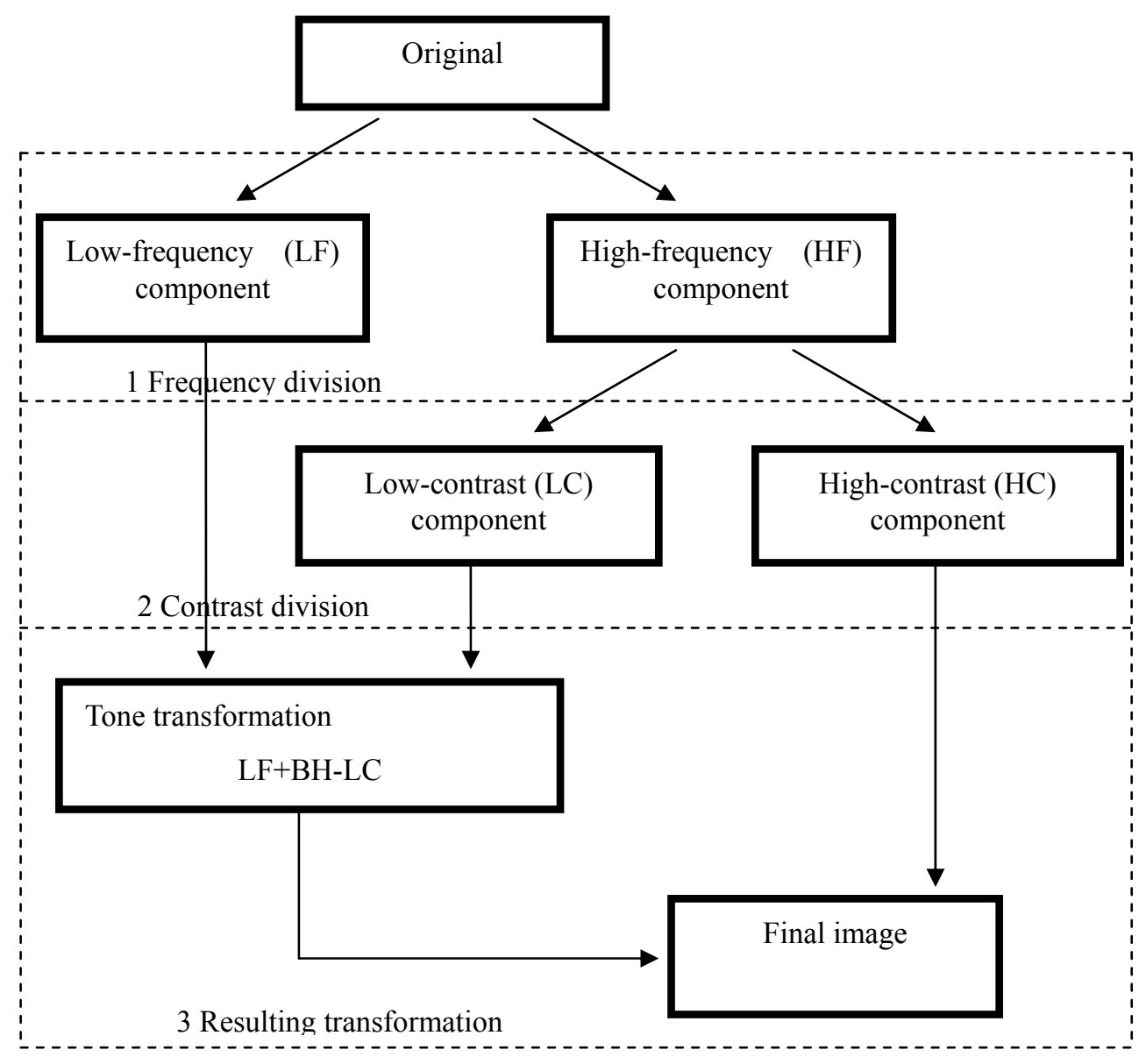

Figure 2. Scheme of image transformation for contour information preservation when changing viewing conditions

\subsubsection{Indirect Methods of Digitization}

To produce high quality digital copies of material culture objects with reproduction coverage largely exceeding registration system capabilities it makes sense to use special processing techniques. Most effective technique is multiple digital registration in different ranges of variation of individual indicators of quality evaluation with following assembling in a single file - digital copy (archived digital image). For example, it's separate digitization of original's lights, shades and half-tones regarding tone content registration. For the purpose of registration of colours of substantial satiation it's also effectually to use several cycles (unit process) of digitization, each of which corresponds to preferential registration of colours corresponding to one of registering device receivers. For frequency content extension digitization can be carried out in stages with different scale (enlargement) of image fragments. It also can be carried out by assembling a single image of fragments shot at high-resolution.

In comparison with single-pass digitization all these procedures require additional operations, development of technology, models, and software for assembling. Currently only tone area is well developed - so-called HDRI-technology (Jacobs, 2007). We've also carried out work cycle regarding HDRI-technology enhancement (Vinokur, 2009). The novelty involves introduction of a new object - virtual original - digital file, which describes frequency, tone and colour content of the source image (original) without losses. Its reproduction coverage is so large that is exceeds capabilities of modern and even advanced systems of registration and reproduction. Special algorithms and, probably, equipment are needed to produce it and get subsequent image reproduction.

Series of steps is the following. Digitization elementary process is modeled. It's important that a model includes parameter that can be called expositional by the analogy with shooting process. It's a vector for tone tasks solution. Its small value corresponds to image light tones, large value - to shades. This parameter is a vector, 
colored exposition for registration of colour content. The number of components corresponds to the number of registering device receivers. Physical meaning of the parameter for frequency content registration corresponds to view size, and not to exposition.

In a general case original coverage is decomposed into subsets, each of which is equal to registration system coverage by its volume. Unification of subsets contains original coverage, and subsets themselves are such that there is nonempty intersection for each of them at least with one of other subsets. Each subset is defined by expositional parameter. One or another subrange of image quality indicator is registered depending on parameter value. Expositional parameter values used when registering are selected in such a way that total number of subsets is least of the possible ones. Each elementary process of registration allows producing a separate digital file. Closing stage is assembling that involves obtaining a final file - the digital copy of material culture object. Assembling accuracy is checked by matching MCO tristimulus values and corresponding pixels of its digital copy. In practical terms sometimes it's more convenient to formulate criterion of accuracy in a differential form in terms of the requirements for equality of relative differences of tristimulus values for MCO selected point.

\section{Discussion}

\subsection{Reproduction Quality Evaluation}

The following technique is possible (reasonably) to use for image reproduction quality evaluation. The point is in matching initial original reproduction coverages with its image obtained as a result of visualization. Reproduction coverages evaluation should be carried out with regard to viewing conditions. When optimizing reproduction, the requirement of equality of visualized image coverage and minimum coverage in the pair \{original coverage, chosen reproduction system coverage\} can be made. This approach provides minimal information losses. In addition, it's necessary to use requirement for reproduction creative tasks accomplishment as an optimality criterion. In this chain digital archived fail of the original is source one. It is transformed into a digital image, reproduction coverage of which corresponds to reproduction coverage of a given reproduction system. Then directly reproduction takes place. The thirst transformation contains a creative component and, in a general case, is not formalized, although it can be carried out automatically to get initial approximation to the final image. The second task is solely technical one and can be solved by ICC- profiling means. The described approach a bit differs from reproduction ideology accepted for today, in particular, it excludes profiling regarding different viewing conditions. However, in author's opinion, it appears more transparent by the aims of each stage and, therefore, preferential to produce the better results artistically and technically.

\subsection{Requirements to Image Digital Copy}

It's of importance that digitization is carried out once and, consequently, there is a single digital archive file. And visualization systems can and will be changed in the course of time, becoming more and more perfect, i.e. having greater and greater reproduction coverage by all quality indicators.

What requirements should be made for image digital copy in terms of indefinite archival storage? Generally, the answer can be the following (Vinokur, 2009): the digital file should contain data, the use of which makes it's possible to restore all information about frequency, tone and colour content of the original within reproduction coverage of chose system of visualization (i.e. to maximally use visualization system capabilities). Since storage is indefinite, reproduction coverage of reproduction system at the limit will be not less than original coverage. In other words, we conclude that even now at the stage of digitization of original images we should tend to code full coverage of the original without frequency, tone and colour distortions, i.e. strain after facsimile accuracy of reproduction.

This issue is principal and it should be given careful considerations. Technological and technical progress continuously increases reproduction coverage of registration process, however, it seems probable that some objects of material culture, which have greater reproduction coverage than registration coverage, will remain. Put it otherwise, even in indeterminate distant future we will have to solve problems of coverage mismatch (this especially applies to frequency content).

\section{Conclusion}

Much attention was paid to image information as main form of data storage regarding objects of material culture in the databases of digital heritage. It creates optimality criterion and allows comparing copies, and also developing protection means for content copyright holders' and owners' protection in the future, and also protection of users against information of poor quality. These measures are necessary to support information security.

It's suggested to make digital copies with minimum loss of information, following the approach even when 
necessary parameters of the file exceed physical capabilities of equipment. Approaches to indirect methods of digitization as exemplified by HDRI technology for high-contrast originals registration are considered. Ways of spreading main ideas of this technology for colour and contrast content registration are sketched.

Various approaches to matching reproduction coverage of digital copies and image demonstration systems are addressed. The problem of the need for producing master copies for each system of reproduction is stated. Approach to its construction is proposed.

Implementation of offered approaches and algorithms, many of which are tested when creating information systems of image processing, will allow achieving the following purposes:

- minimization of information losses when registering and reproducing images;

- indefinite archival storage providing high technical quality of image reproduction, particularly in years to come when major changes in the parameters of reproduction systems take place (no need for repeated digitization)

- universality of digital originals for any multimedia system.

Findings create basis for further studies in the area of digital heritage information systems application for the purposes of culture and education. Primarily, it is formalization of the notion of digital copying accuracy, the second trend is assurance of high quality reproduction in all systems of visualization, the third one is development of indirect digitization methods.

\section{References}

Artyushin, L. F. (1970). Basics of color reproduction in movie, television, and printing. Moscow: Iskusstvo, 548.

Artyushina, I. L., \& Vinokur, A. I. (1996). Concerning transfer accuracy of tone and structural information in reproduction processes. Collection of scientific papers of research institute of photo and cinema, Methods of cinematography technological advancement using computers, 43-47.

Artyushina, I. L., Ahtariev, R. Zh., \& Vinokur, A. I. (2009). Methods of high-contrast original images recording and reproduction in systems with limited dynamic range. Izvestiya vysshih uchebnyh zavedenyj. Problemy poligrafii i izdatelskogo dela, 4, 9-15.

Artyushina, I. L., Blokhin, A. S., \& Vinokur, A. I. (2005). Electronic digital cinematography. Problems and development prospects. Tekhnika kino i televideniya, 5-6(54-56), 7-8(56-57).

Artyushina, I. L., Vinokur, A. I., \& Sergeev, S. A. (1989). Auto-typical polychromatic synthesis equations. Zhurnal nauchnoy i prikladnoy fotografii i kinematografii, 34(5), 352-356.

Artyushina, I. L., Vinokur, A. I., \& Titov, A. S. (2006). Colour reproduction modeling in flexographic printing based on Nuberg-Neugebauer equation. Izvestiya vysshih uchebnyh zavedenyj. Problemy poligrafii $i$ izdatelskogo dela, 4, 214-220.

Barladyan, B. Kh., Voloboy, A. G., Galaktionov, V. A., \& Kopylov, E. A. (2004). Effective contraction operator of brightness dynamic range. Programmirovanie, 5, 35-42.

Belousov, A. A., Vinokur, A. I., \& Vasin, M. S. (2003). Tehnologiya kopirovaniya arhivnyh filmovyh materialov. Moscow: NIKFI.

Caffo, R. (2014). Digital Cultural Heritage Projects: Opportunities and Future Challenges. Procedia Computer Science, 38, 12-17. http://dx.doi.org/10.1016/j.procs.2014.10.003

Fairchild, M. D. (2004). Color appearance models (2nd Ed.). Boston: Addison Wesley Longman.

Fraser, B., Murphy C., \& Bunting, F. (2003). Real World Color Management (2nd Ed.). San Francisco, SF: Peachpit Press.

Hauttekeete, L., Evens, T., De Moor, K., Schuurman, D.,Mannens, E., \& Van de Walle, R. (2011). Archives in motion: Concrete steps towards the digital disclosure of audiovisual content. Journal of Cultural Heritage, 12, 459-465. http://dx.doi.org/10.1016/j.culher.2011.04.004

Hughes, L. (2004). Digitizing Collections: Strategic issues for the information manager. London: Facet Publishing.

Hunt, R. W. G. (2004). The Reproduction of Color (6th ed.). England: Fountain Press. http://dx.doi.org/10.1002/0470024275

Iannucci, A., Parmeggiani, A., \& Zaccarini, M. (2011). E-learning in humanities in Italian universities: A 
preliminary report. Procedia - Social and Behavioral Sciences, 28, 729-738. http://dx.doi.org/10.1016/j.sbspro.2011.11.135

Jacobs, A. (2007). High Dynamic Range Imaging and its Application in Building Research. Advances in Building Energy Research, 1, 77-202. http://dx.doi.org/10.1080/17512549.2007.9687274

Kenney, A. R., \& Rieger, O. Y. (2000). Moving Theory into Practice: Digital imaging for libraries and archives. Mountain View, Calif.: Research Libraries Group.

Krstev, C., \& Trtovac A. (2014). Teaching Multimedia Documents to LIS Students. The Journal of Academic Librarianship, 40, 152-162. http://dx.doi.org/10.1016/j.acalib.2014.02.006

Lee, S. D. (2001). Digital Imaging: A practical handbook. London: Library Association.

Liu, J. P. (2001). Owning Digital Copies: Copyright Law and the Incidents of Copy Ownership, 42 Wm. and Mary L. Rev. 1245. Retrieved from http://scholarship. law. wm. edu/wmlr/vol42/iss4/5

MacDonald, L. (2006). Digital Heritage: Applying digital imaging to cultural heritage. Elsevier Butterworth-Heinemann, Oxford.

Matusiak, K. K. (2006). Information Seeking Behavior in Digital Image Collections: A Cognitive Approach. The Journal of Academic Librarianship, 32, 479-488. http://dx.doi.org/10.1016/j.acalib.2006.05.009

McLeod, L., Broady-Preston, J., \& Atkins, R. (2014). Accessing Humanities Research in a Digital Environment. Procedia - Social and Behavioral Sciences, 147, 140-146. http://dx.doi.org/10.1016/j.sbspro.2014.07.130

Meyer, É., Grussenmeyer, P., Perrin, J. P., Durand, A., \& Drap, P. (2007). A web information system for the management and the dissemination of Cultural Heritage data. Journal of Cultural Heritage, 8, 396-411. http://dx.doi.org/10.1016/j.culher.2007.07.003

Note, M. (2011). Managing Image Collections: A Practical Guide. Oxford: Chandos Publishing. http://dx.doi.org/10.1533/9781780630564

Nuberg, N. D. (1948). Theoretical framework colour reproduction. Moscow: Sovetskaya nauka, 176.

Panarin, I. N. (2004). Cyberwar and diplomacy. Moscow: Gorodets, 528.

Psychophysiology basics. (1998). Aleksndrov, Y. I. (editor). Moscow: INFRA-M, 432.

Ritzenthaler, M., \& Vogt-O'Connor, D. et al. (2006). Photographs: Archival care and management. Chicago: Society of American Archivists.

Simón, L. F. R., Avilés, R. A., Botezan, I., del Valle Gastaminza, F., \& SerranoS. C. (2014). Open Data as Universal Service. New perspectives in the Information Profession. Procedia - Social and Behavioral Sciences, 147, 126-132. http://dx.doi.org/10.1016/j.sbspro.2014.07.128

Skov, M., \& Ingwersen, P. (2014). Museum Web search behavior of special interest visitors. Library \& Information Science Research, 36, 91-98. http://dx.doi.org/10.1016/j.lisr.2013.11.004

Styliadis, A. D., Akbaylar, I. I., Papadopoulou, D. A., Hasanagas, N. D., Roussa, S. A., \& SexidisL. A. (2009). Metadata-based heritage sites modeling with e-learning functionality. Journal of Cultural Heritage, 10, 296-312. http://dx.doi.org/10.1016/j.culher.2008.08.014

Vinokur, A. I. (2009). The conception of multimedia presentation of historical-cultural materials. Tsifrovoe nasledie, 1, 61-63.

Yashtold-Govorko, V. A. (1968). Photographic images printing. Moscow: Iskusstvo, 214.

\section{Copyrights}

Copyright for this article is retained by the author(s), with first publication rights granted to the journal.

This is an open-access article distributed under the terms and conditions of the Creative Commons Attribution license (http://creativecommons.org/licenses/by/3.0/). 